\title{
Trivalent actinide ions showing tenfold coordination in solution
}

- Supporting Information -

Patrik Weßling, ${ }^{*, a, b}$ Tobias Schenk, ${ }^{\mathrm{b}}$ Felix Braun, ${ }^{\mathrm{b}}$ Björn B. Beele, ${ }^{\mathrm{c}}$ Sascha Trumm, ${ }^{\mathrm{d}}$ Michael Trumm, ${ }^{\mathrm{a}}$ Bernd Schimmelpfennig, ${ }^{\mathrm{a},{ }^{\dagger}}$ Dieter Schild, ${ }^{\mathrm{a}}$ Andreas Geist, ${ }^{\mathrm{a}}$ and Petra J. Panak ${ }^{\mathrm{a}, \mathrm{b}}$

${ }^{\text {a }}$ Karlsruhe Institute of Technology (KIT), Institute for Nuclear Waste Disposal (INE), P. O. Box 3640, 76021 Karlsruhe, Germany

${ }^{\mathrm{b}}$ Ruprecht-Karls-Universität Heidelberg, Institut für Physikalische Chemie, Im Neuenheimer Feld 253, 69120 Heidelberg, Germany

${ }^{\mathrm{c}}$ Bergische Universität Wuppertal, Inorganic Chemistry, Gaußstraße 20, 42119 Wuppertal, Germany

${ }^{\mathrm{d}}$ Karlsruhe Institute of Technology (KIT), Center for Advanced Technological and Environmental Training (FTU), P. O. Box 3640, 76021 Karlsruhe, Germany

${ }^{+}$Deceased: 09/13/19 
Trivalent actinide ions showing tenfold coordination in solution
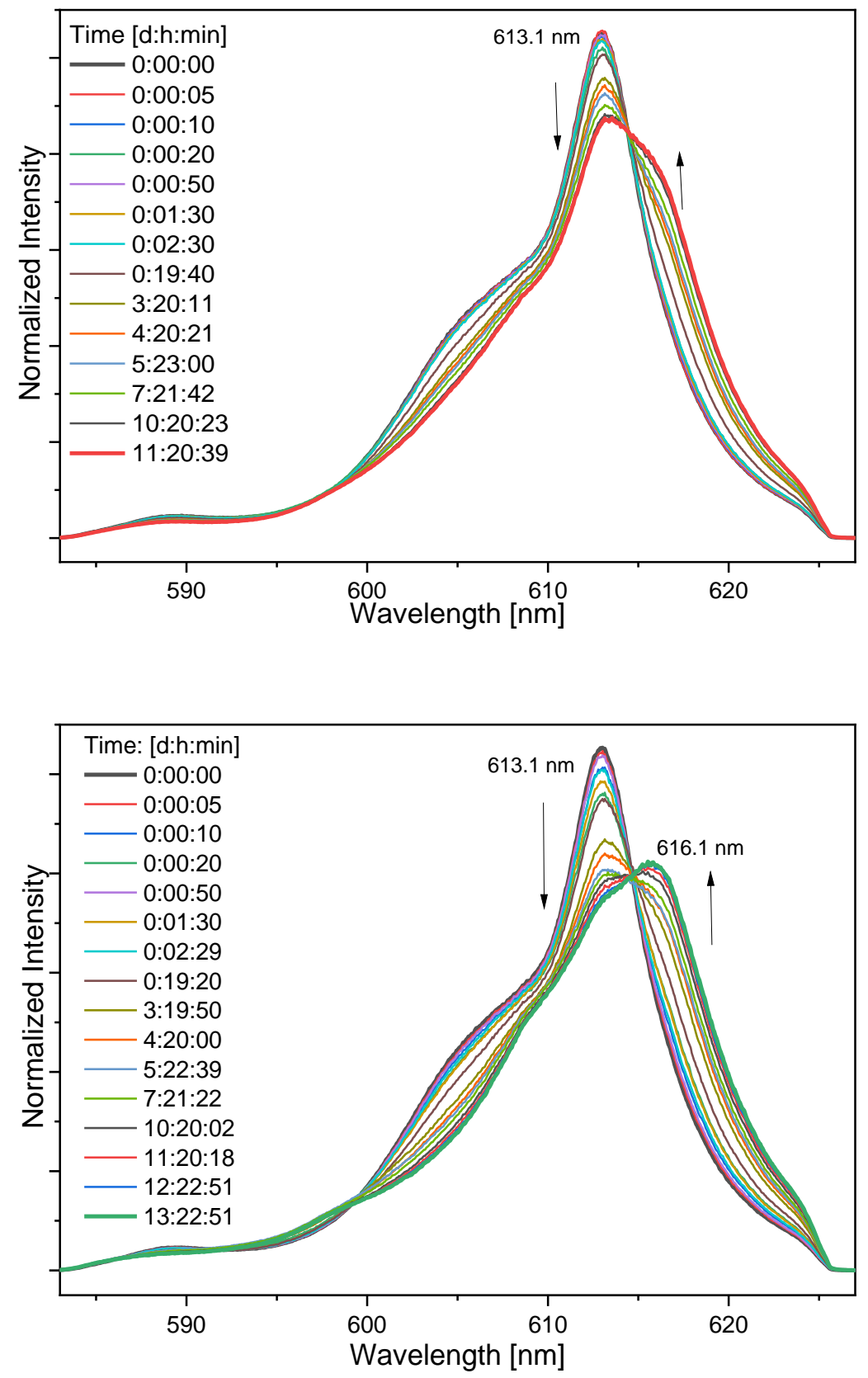

Fig. S1. Normalized Cm(III) emission spectra in 2-propanol containing 2.5 vol.\% $\mathrm{H}_{2} \mathrm{O}$ (top) and 5 vol. $\% \mathrm{H}_{2} \mathrm{O}$ (bottom) as a function of time after the addition of nitrate. $[\mathrm{Cm}(\mathrm{III})]_{\text {ini }}=$ $1 \cdot 10^{-7} \mathrm{~mol} / \mathrm{L} ;[$ TBAN $]=4.03 \cdot 10^{-4} \mathrm{~mol} / \mathrm{L} ;[\mathrm{nPr}-\mathrm{BTP}]=1.58 \cdot 10^{-5} \mathrm{~mol} / \mathrm{L}$. 
Trivalent actinide ions showing tenfold coordination in solution

— Supporting Information —

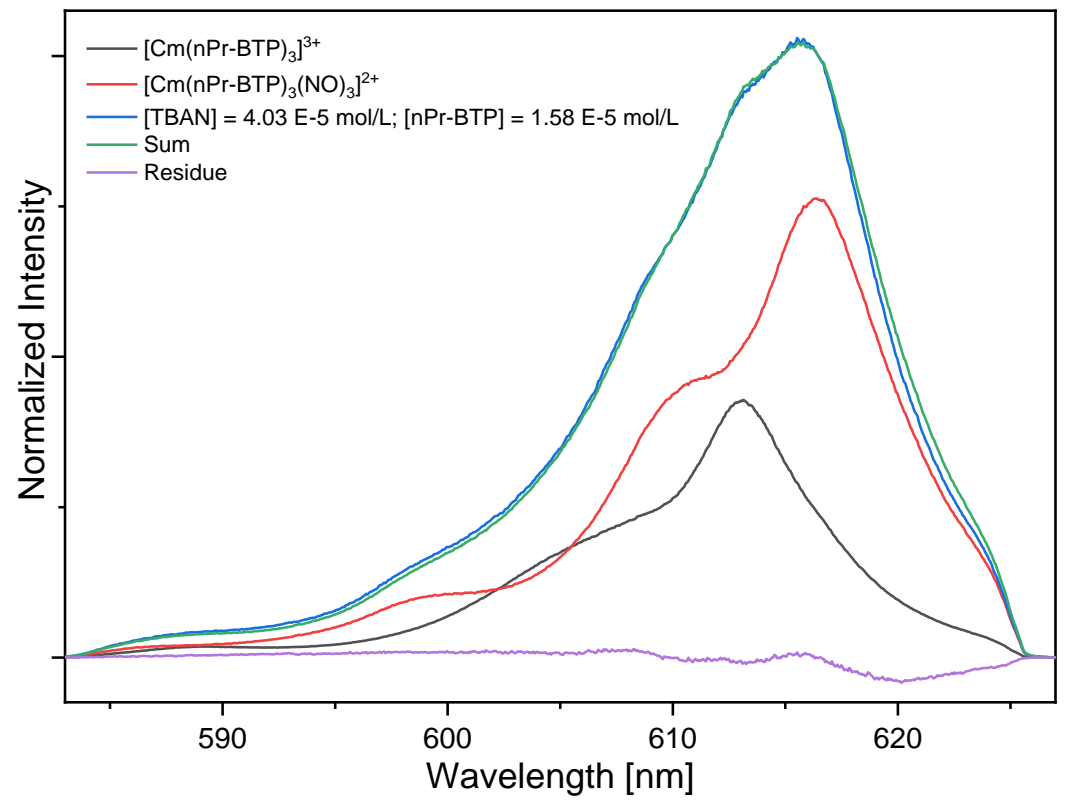

Fig. S2. Peak deconvolution of a Cm(III) emission spectrum in 2-propanol containing 5 vol.\% $\mathrm{H}_{2} \mathrm{O} .[\mathrm{Cm}(\mathrm{III})]_{\text {ini }}=1 \cdot 10^{-7} \mathrm{~mol} / \mathrm{L} ;[\mathrm{TBAN}]=4.03 \cdot 10^{-5} \mathrm{~mol} / \mathrm{L} ;[\mathrm{nPr}-\mathrm{BTP}]=1.58 \cdot 10^{-5} \mathrm{~mol} / \mathrm{L}$. 
Trivalent actinide ions showing tenfold coordination in solution

— Supporting Information —
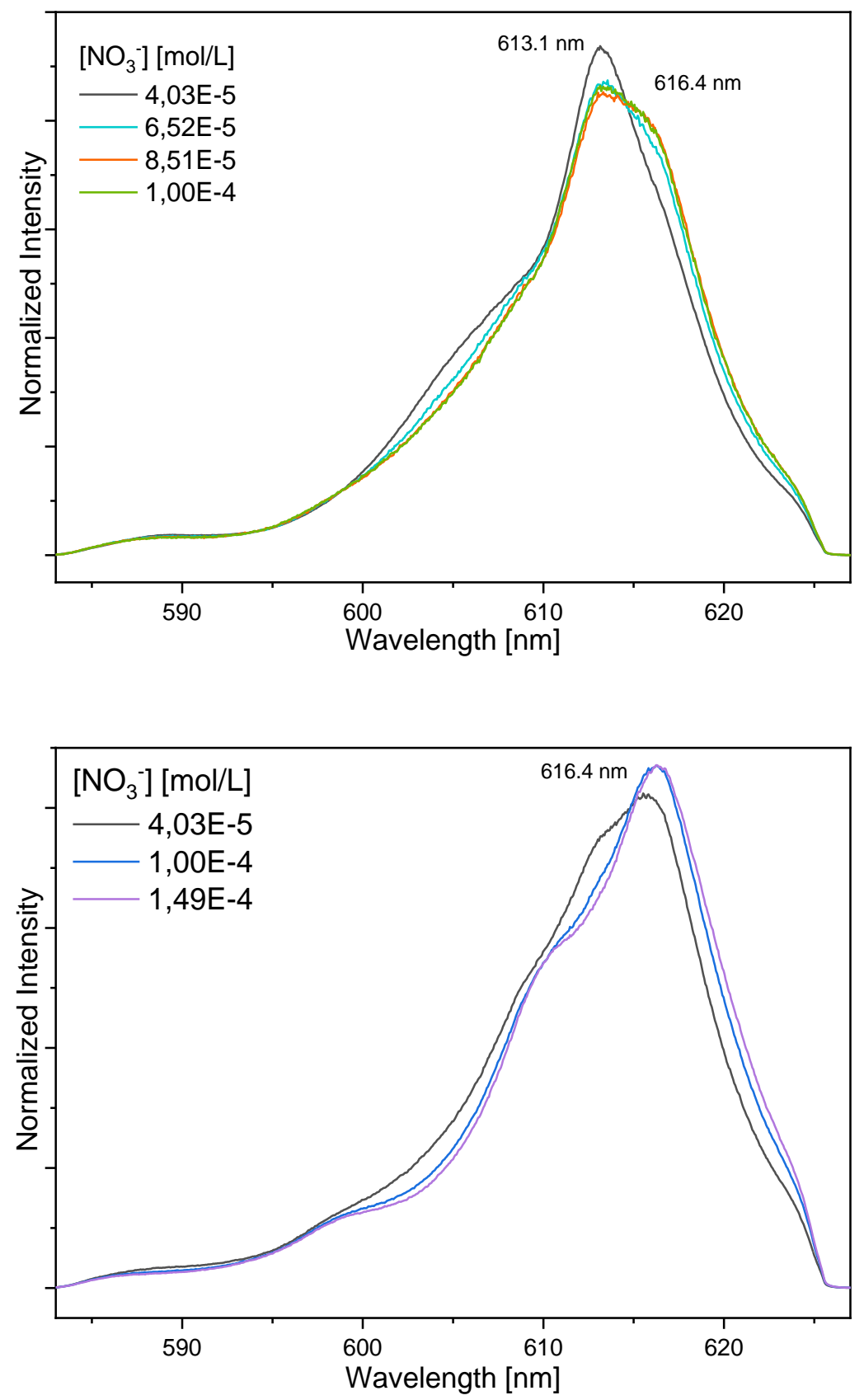

Fig. S3. Normalized Cm(III) emission spectra in 2-propanol (top) and 2-propanol containing 5 vol. $\% \mathrm{H}_{2} \mathrm{O}$ (bottom) as a function of the nitrate concentration. $[\mathrm{Cm}(\mathrm{III})]_{\mathrm{ini}}=1 \cdot 10^{-7} \mathrm{~mol} / \mathrm{L}$; $[\mathrm{nPr}-\mathrm{BTP}]=1.58 \cdot 10^{-5} \mathrm{~mol} / \mathrm{L}$. 
Trivalent actinide ions showing tenfold coordination in solution

— Supporting Information -

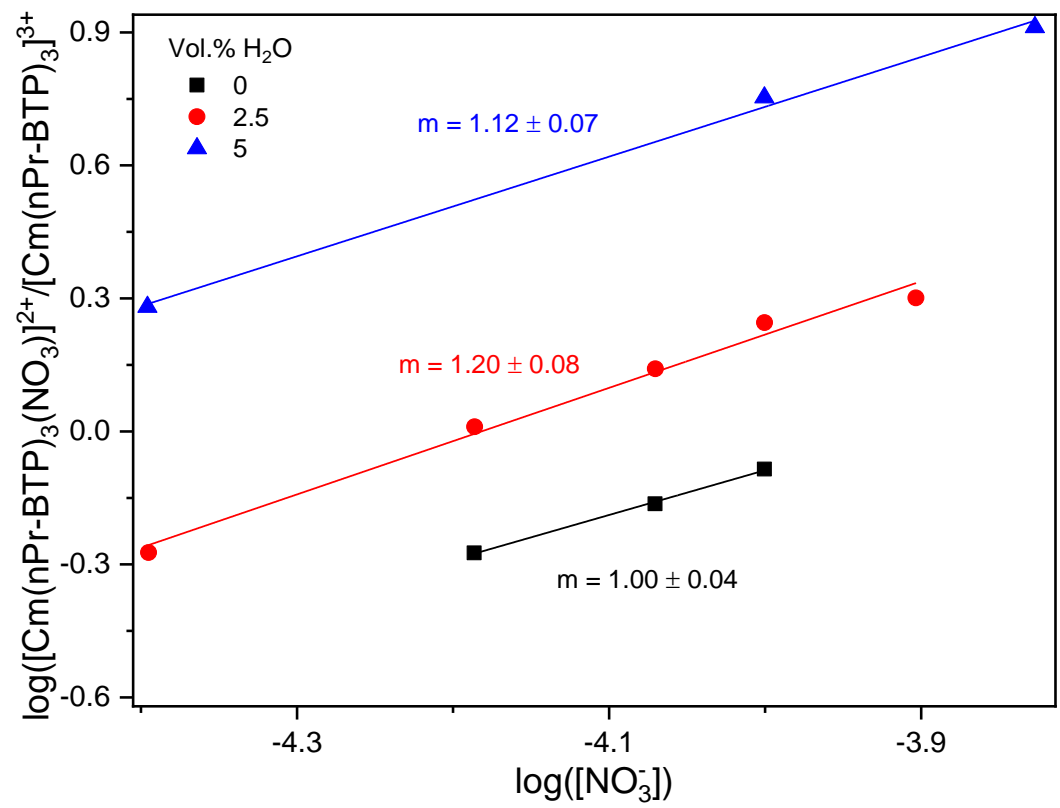

Fig. S4. Double logarithmic plot of the ratio of the molar fraction of species 1 and $\left[\mathrm{Cm}(\mathrm{nPr}-\mathrm{BTP})_{3}\right]^{3+}$ versus the nitrate concentration.

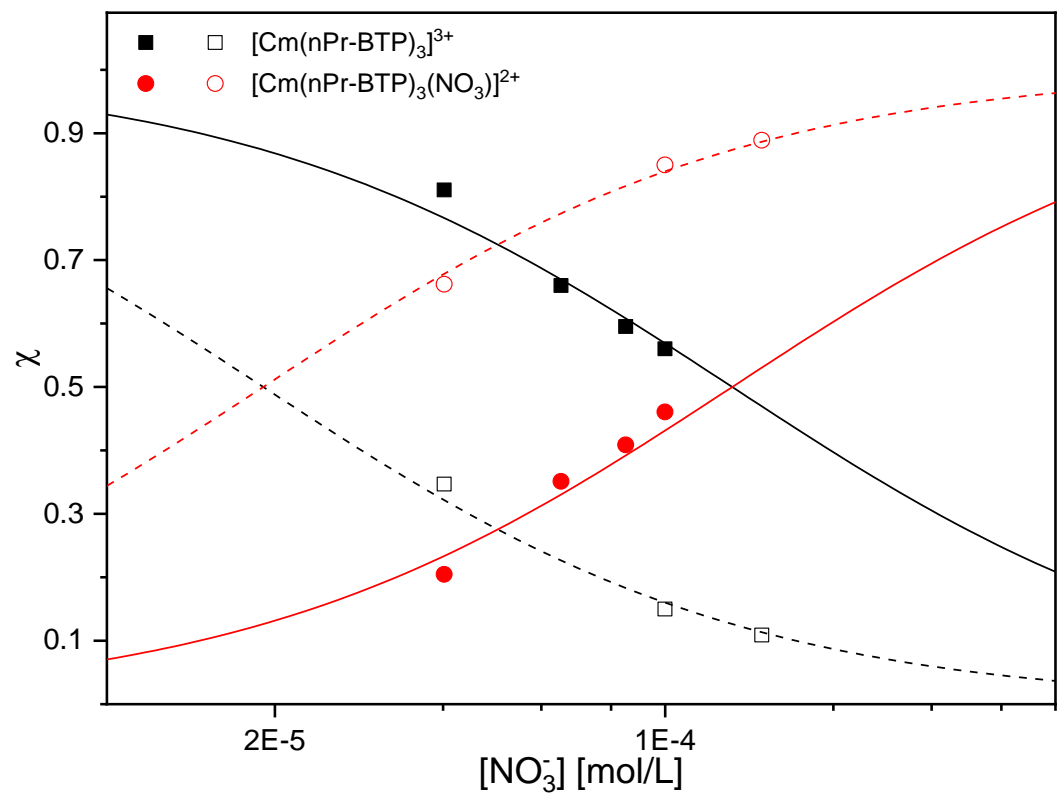

Fig. S5. Molar fractions of $\left[\mathrm{Cm}(\mathrm{nPr}-\mathrm{BTP})_{3}\right]^{3+}$ and $\left[\mathrm{Cm}(\mathrm{nPr}-\mathrm{BTP})_{3}\left(\mathrm{NO}_{3}\right)\right]^{2+}$ in 2-propanol (closed symbols) and 2-propanol containing 5 vol. $\% \mathrm{H}_{2} \mathrm{O}$ (open symbols) as a function of the nitrate concentration. Lines are calculated with $\log \beta^{\prime}=3.9$ (2-propanol, continuous lines) and $\log \beta^{\prime}=4.7$ (2-propanol +5 vol. $\% \mathrm{H}_{2} \mathrm{O}$, dashed lines). 
Trivalent actinide ions showing tenfold coordination in solution — Supporting Information —
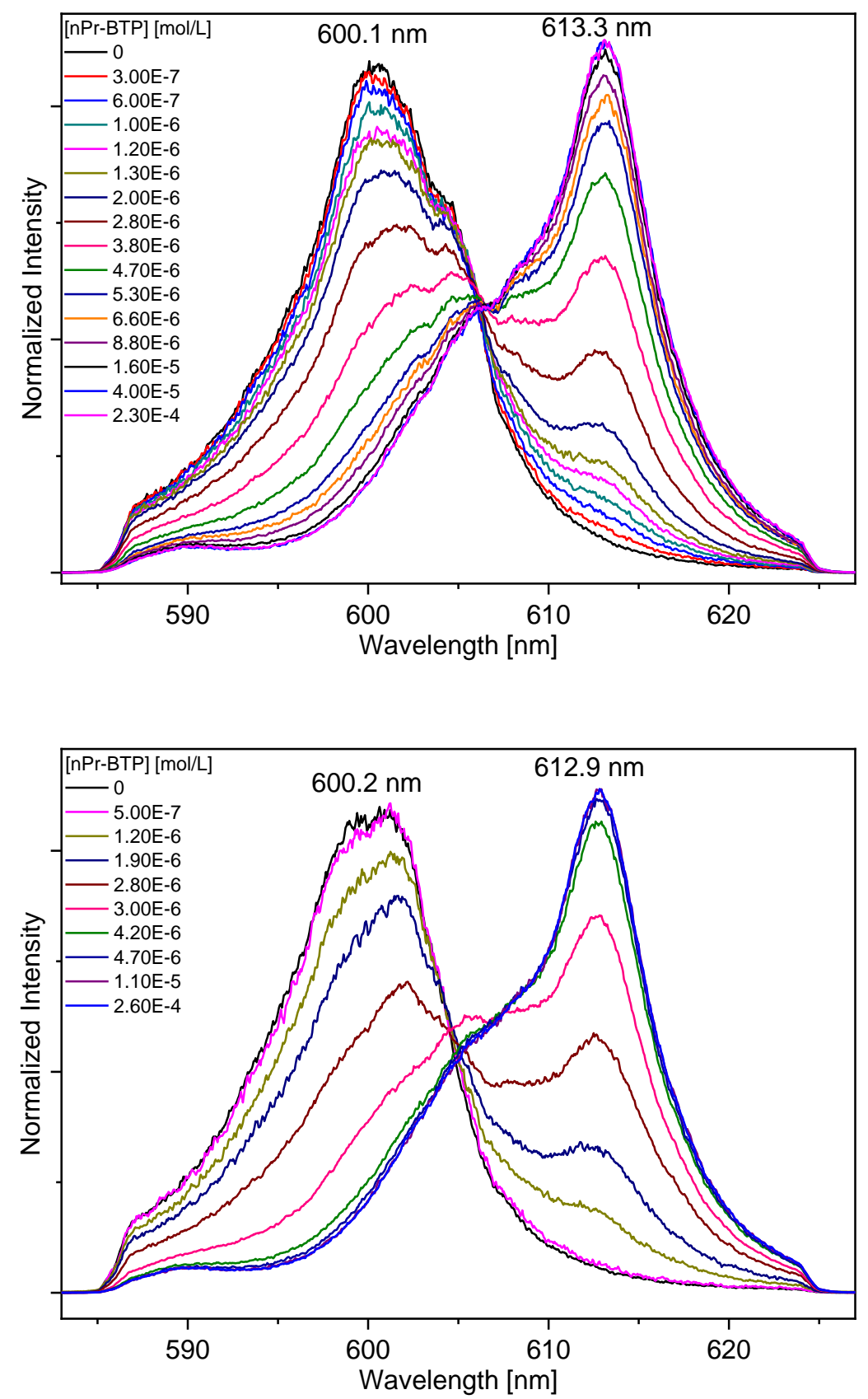

Fig. S6. Normalized Cm(III) fluorescence spectra as a function of the nPr-BTP concentration in methanol with constant cyanide (top) and triflate (bottom) concentration. $[\mathrm{Cm}(\mathrm{III})]_{\mathrm{ini}}=$ $2 \cdot 10^{-7} \mathrm{~mol} / \mathrm{L} ;\left[\mathrm{CN}^{-}\right]=\left[\mathrm{OTf}^{-}\right]=2 \cdot 10^{-5} \mathrm{~mol} / \mathrm{L}$. 
Trivalent actinide ions showing tenfold coordination in solution

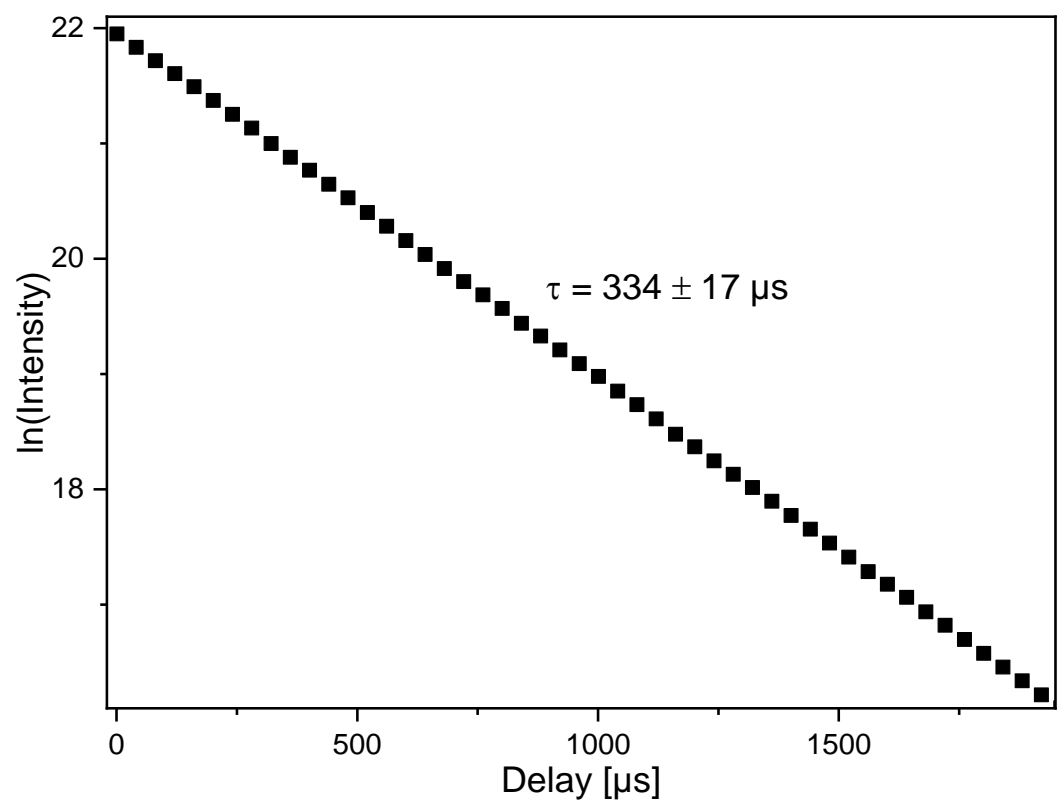

Fig. S7. Decay of the Cm(III) fluorescence intensity as a function of the delay time in 2propanol with $1.6 \cdot 10^{-5} \mathrm{~mol} / \mathrm{L} \mathrm{nPr}-\mathrm{BTP}$ and $4.03 \cdot 10^{-5} \mathrm{~mol} / \mathrm{L}$ TBAN containing $2.5 \mathrm{vol} . \%$ $\mathrm{H}_{2} \mathrm{O} .[\mathrm{Cm}(\mathrm{III})]_{\text {ini }}=1 \cdot 10^{-7} \mathrm{~mol} / \mathrm{L}$.

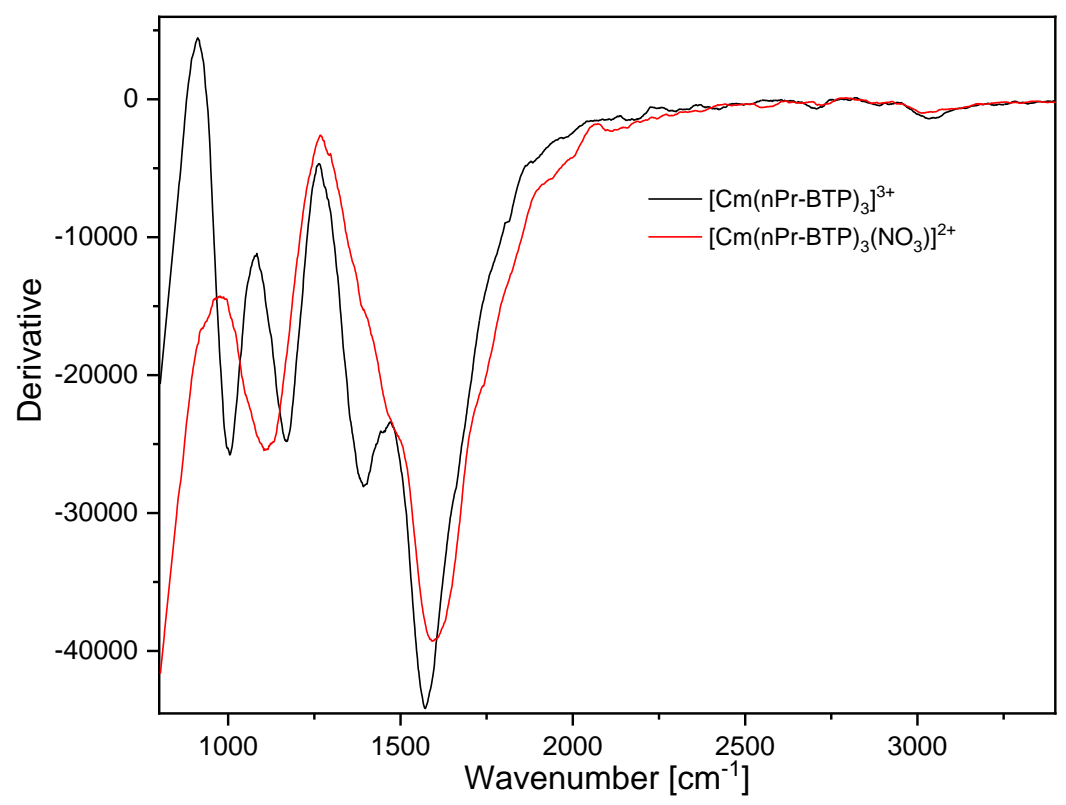

Fig. S8. Derivative of the VSB spectrum of $\left[\mathrm{Cm}(\mathrm{nPr}-\mathrm{BTP})_{3}\right]^{3+}$ in 2-propanol $\left([\mathrm{Cm}(\mathrm{III})]_{\mathrm{ini}}=1 \cdot 10^{-7} \mathrm{~mol} / \mathrm{L} ;[\mathrm{nPr}-\mathrm{BTP}]=2.23 \cdot 10^{-5} \mathrm{~mol} / \mathrm{L}\right)$ and VSB spectrum of a Cm(III) sample containing $64 \%\left[\mathrm{Cm}(\mathrm{nPr}-\mathrm{BTP})_{3}\left(\mathrm{NO}_{3}\right)\right]^{2+}$ in 2-propanol with $2.5 \mathrm{vol} . \% \mathrm{H}_{2} \mathrm{O}$ $\left([\mathrm{Cm}(\mathrm{III})]_{\mathrm{ini}}=1 \cdot 10^{-7} \mathrm{~mol} / \mathrm{L} ;[\mathrm{TBAN}]=1 \cdot 10^{-4} \mathrm{~mol} / \mathrm{L} ;[\mathrm{nPr}-\mathrm{BTP}]=1.6 \cdot 10^{-5} \mathrm{~mol} / \mathrm{L}\right)$. 
Trivalent actinide ions showing tenfold coordination in solution

\section{Position a}

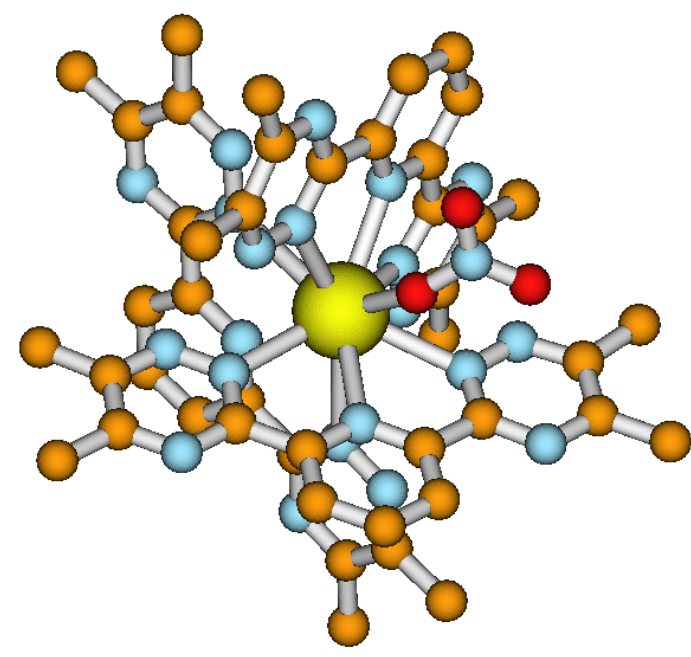

\section{Position c}

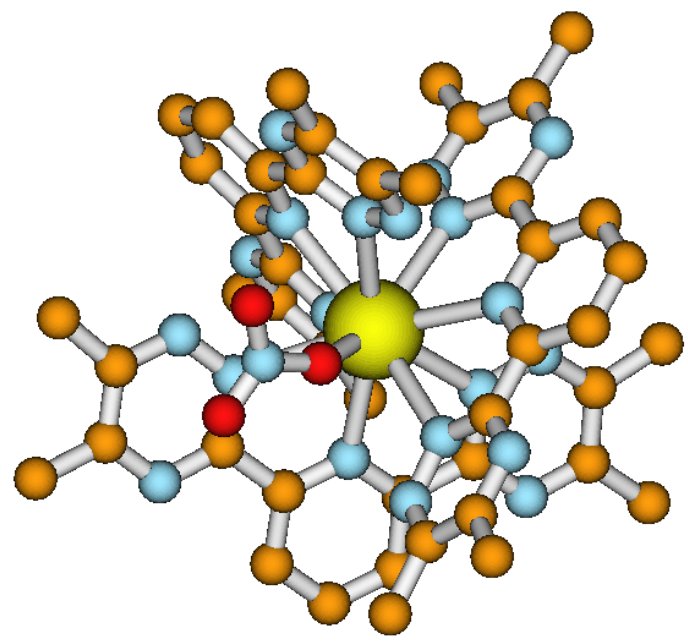

\section{Position d}

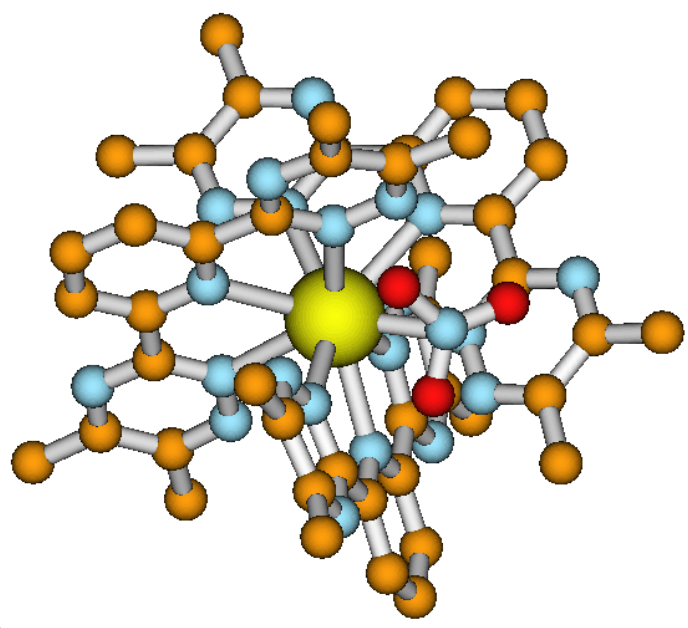

Fig. S9. Optimized structures of $\left[\mathrm{Cm}(\mathrm{Me}-\mathrm{BTP})_{3}\left(\mathrm{NO}_{3}\right)\right]^{2+}$. Top, nitrate on the $\mathrm{C}_{2}$ axis, short initial $\mathrm{Cm}-\mathrm{NO}_{3}{ }^{-}$distance. Middle, nitrate 'on the $\mathrm{C}_{3}$ axis, short initial $\mathrm{Cm}-\mathrm{NO}_{3}{ }^{-}$distance. Bottom, nitrate on the $\mathrm{C}_{3}$ axis, long initial $\mathrm{Cm}-\mathrm{NO}_{3}{ }^{-}$distance. $\mathrm{C}$, brown; $\mathrm{N}$, blue; $\mathrm{O}$, red; $\mathrm{Cm}(\mathrm{III})$, yellow. Hydrogen atoms omitted for clarity. 
Trivalent actinide ions showing tenfold coordination in solution
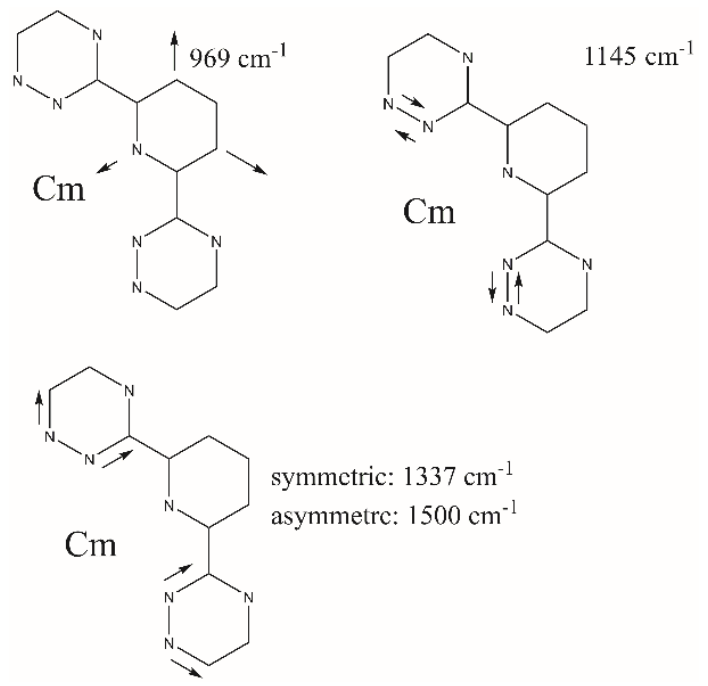

Fig. S10. Simplified representation of the vibrational modes of the BTP framework of $\left[\mathrm{Cm}(\mathrm{Me}-\mathrm{BTP})_{3}\right]^{3+}$ and $\left[\mathrm{Cm}(\mathrm{Me}-\mathrm{BTP})_{3}\left(\mathrm{NO}_{3}\right)\right]^{2+}$.

\begin{tabular}{|c|c|c|c|}
\hline & 1 & 2 & 3 \\
\hline$\delta$ & $v$ & & \\
\hline & &
\end{tabular}

Fig. S11. Simplified representation of the $\mathrm{NO}_{3}{ }^{-}$vibrational modes in $\left[\mathrm{Cm}(\mathrm{Me}-\mathrm{BTP})_{3}\left(\mathrm{NO}_{3}\right)\right]^{2+}$. 
Trivalent actinide ions showing tenfold coordination in solution

- Supporting Information —
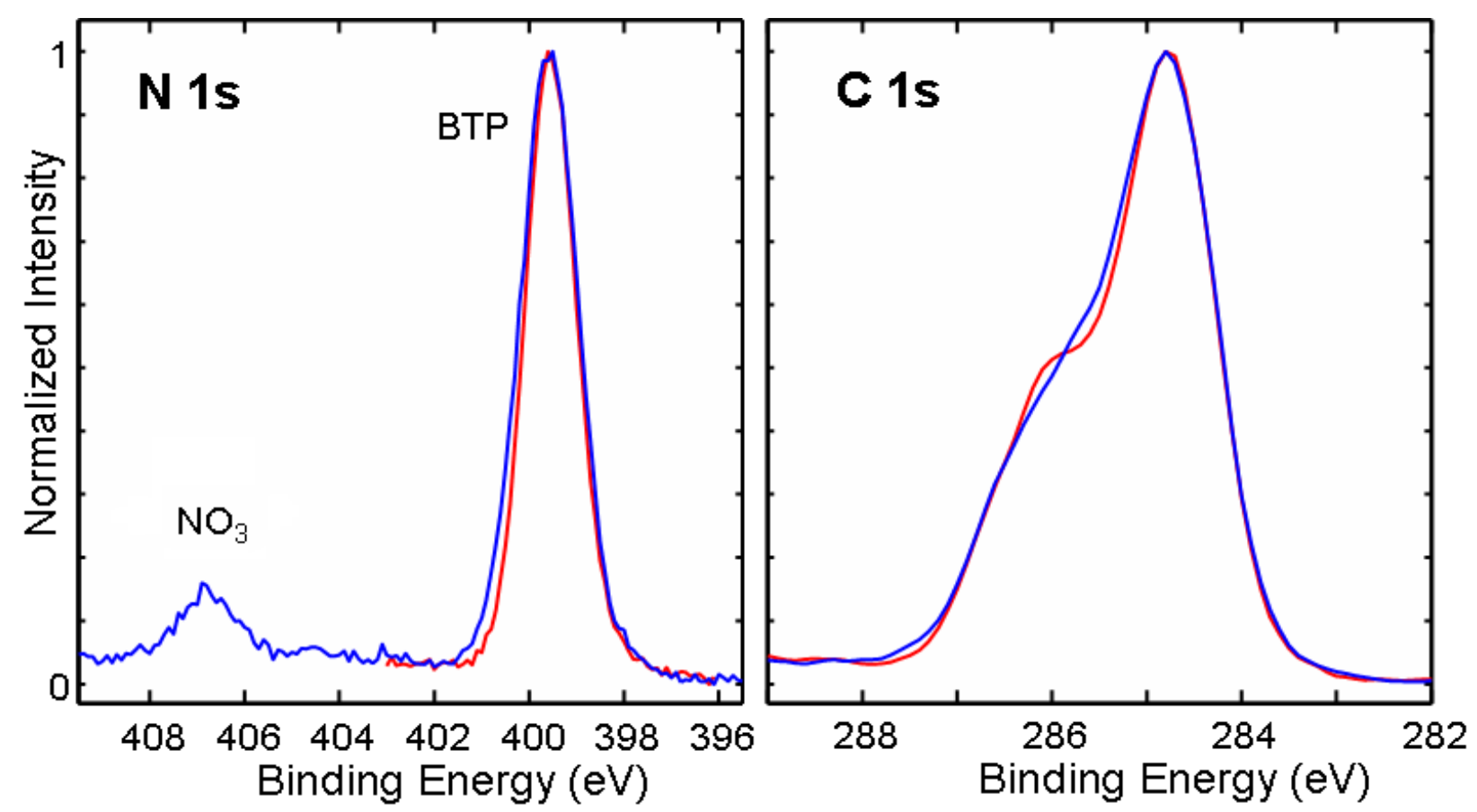

Fig. S12. N 1s (left) and C 1s (right) photoelectron spectra of nPr-BTP (red curve) in 2propanol and $\mathrm{nPr}-\mathrm{BTP} \cdot \mathrm{HNO}_{3}$ (blue curve) in 2-propanol with $0.15 \mathrm{~mol} / \mathrm{L} \mathrm{HNO}_{3}$. $[\mathrm{nPr}-\mathrm{BTP}]=3 \cdot 10^{-3} \mathrm{~mol} / \mathrm{L}$. 
Trivalent actinide ions showing tenfold coordination in solution

— Supporting Information —

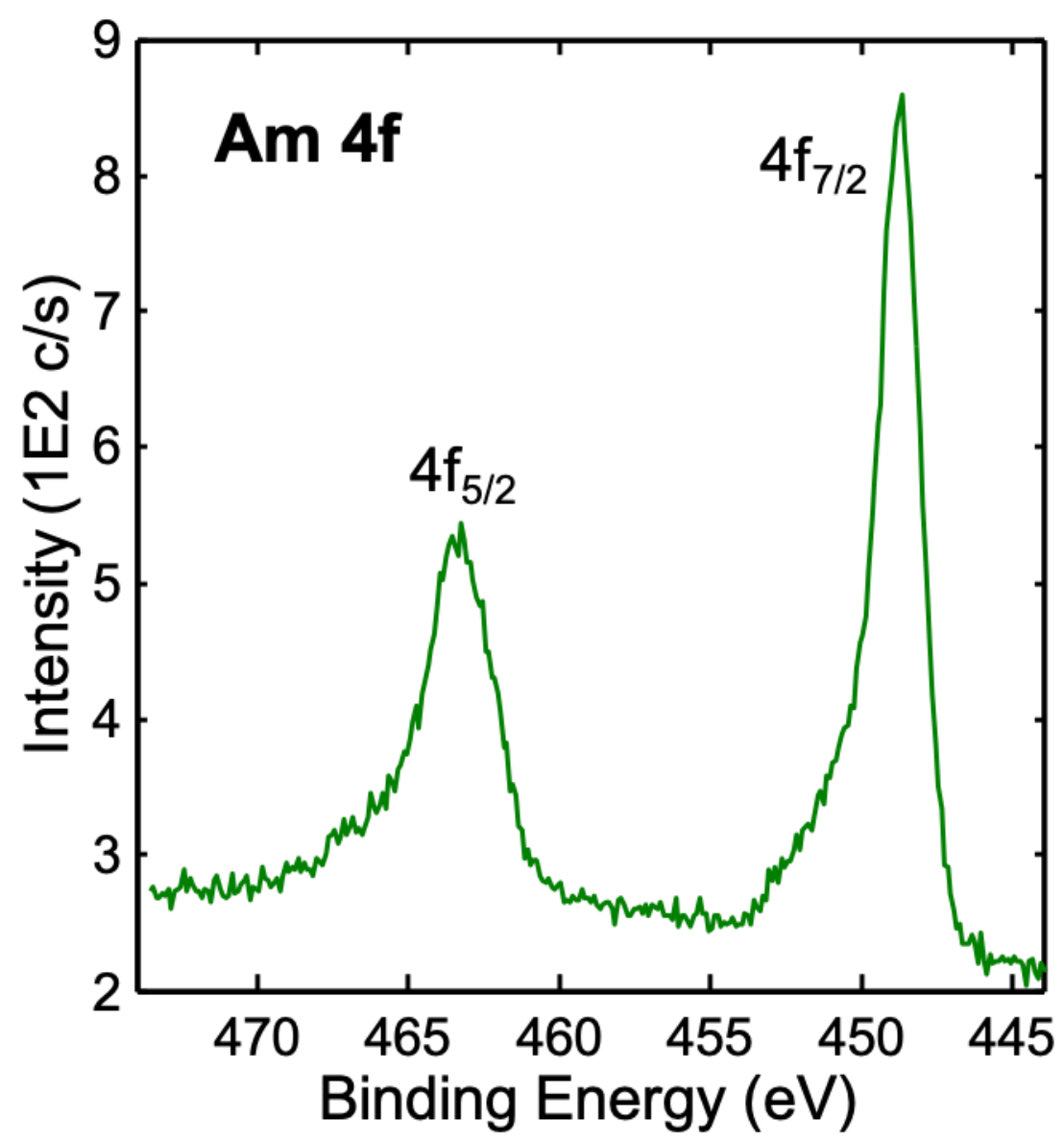

Fig. S13. Am $4 \mathrm{f}$ photoelectron spectrum of $\left[\mathrm{Am}(\mathrm{nPr}-\mathrm{BTP})_{3}\left(\mathrm{NO}_{3}\right)\right]\left(\mathrm{NO}_{3}\right)_{2} \cdot \mathrm{HNO}_{3}$. The binding energy of $\mathrm{Am}_{4 \mathrm{f}_{7 / 2}}$ is $448.7 \mathrm{eV}$ (FWHM $1.74 \mathrm{eV}$ ) and the $4 \mathrm{f}$ spin-orbit splitting $14.6 \mathrm{eV}$. 